\title{
Total Body Clearance for Dose Interval Normalized by Body Mass Index
}

National Cancer Institute

\section{Source}

National Cancer Institute. Total Body Clearance for Dose Interval Normalized by Body

Mass Index. NCI Thesaurus. Code C114231.

The total body clearance for intravascular administration for dose interval divided by the body mass index. 